\title{
MODELING OF PROCESS OF OBTAINING ACTIVATED SOLUTIONS IN ELECTROLYZER FOR THEIR USE IN AGRICULTURE
}

\author{
Sergei Oskin, Dmitry Tsokur, Sergey Voloshin \\ Kuban State Agrarian University named after I.T. Trubilin, Russia \\ kgauem@yandex.ru,dmitry_tsokur@mail.ru
}

\begin{abstract}
Various electrical and technological techniques are increasingly used to stimulate the vital activity of animals and plants in agricultural production. Elements of electrical technologies are used to suppress pathogenic microorganisms. Activated solutions obtained as a result of diaphragm electrolysis have the widest range of action. In agriculture, there is a need for electric activators with specific characteristics and they are capable of producing activated solutions with specified properties. It is necessary to study the main physical and chemical processes occurring in electrolyzers and develop appropriate mathematical and computer models. It is proposed to use the Comsol software package for modeling. The geometric model of a non-flowing diaphragm electrolyzer is presented in the form of a cylinder with a capacity of 1 liter. The Navier-Stokes and Joule - Lenz equations were used to describe the thermal processes and the movement of the electrolyte in the activator. Navier-Stokes equations and Darcy's law are used to model transport movements in porous media. The processes occurring in the anode and cathode chambers during the electrode-electrolyte transition were described using the Butler-Folmer equation. The analysis and comparison with experimental data were performed after solving mathematical models and constructing images of the main physical processes. Studies of changes in physical and chemical properties of anolyte and catholyte in a non-stationary period (up to 16 minutes) have shown that the model and experimental data for the most part had a good match after the $12^{\text {th }}$ minute (relative error from 2 to $6 \%$ ). Experimental graphs of changes in the hydrogen index over time in the anode and cathode chambers showed a small discrepancy with the simulation data in the interval of 8-12 minutes (an error of about $11 \%$ ) and a fairly good match at the stationary site (an error of less than $4 \%$ ).
\end{abstract}

Keywords: diaphragm electrolysis, anolyte, catholyte, modeling, agriculture.

\section{Introduction}

Numerous experiments with activated water conducted by researchers [1-5] have shown its high efficiency when used in various agricultural production technologies. Several methods of water activation are used: ultrasound, ozonation, magnetic field treatment, electrolysis, etc [6; 7]. Activation of water solutions by electrolysis gives a higher result and produces two types of activated products. In order to obtain two types of activated solutions, in most cases, diaphragm electrolysis is used. Electrolysis is a complex set of processes: migration of ions (positive to the cathode, negative to the anode), diffusion of ions and their discharge at the electrodes, electrochemical reactions during the discharge of ions, primary and secondary chemical reactions of electrolysis products.

In the process of electrical activation during diaphragm electrolysis, there is a division into two fractions: in the anode chamber (alkaline fraction), in which the chlorine-wadded acid is formed, hypochloride, chlorate and sodium perichlorate, hydrogen peroxide; in the cathode part, hydrogen gas is released, alkali and a large number of hydroxyl ions are formed, and carbonate salts precipitate. Anolyte has antiseptic and bactericidal properties, it is a preservative, and can slow down the vital activity of a living organism and plants. Catholyte, in turn, is a growth stimulant for the development of animals and plants, it has increased dissolving and extracting abilities, and increased absorption and chemical activity. Due to these characteristics, activated solutions are increasingly used in certain agricultural technologies: forage production, silage, decontamination of containers and premises, keeping livestock, ensuring the safety of vegetables and fruits, processing of soil and plants in closed ground, etc [8-19].

Various applications of electrical activated solutions are described in the literature under the authorship of V. M. Bakhir [1;2]. Kuban State Agrarian University also conducts researches on the use of activated water in certain technologies of the agro-industrial complex [20-23]. Numerous researchers in electrolysis processes have repeatedly confirmed the difficulties of describing chemical reactions occurring in electrolyzers. It is difficult to guess what reactions will begin to occur in the first place and it is known that almost all the main ones are reversible. The resulting meta-stable mixtures, as a rule, cannot have the obtained characteristics for a long time. In order to be able to design electrical activators of different performance and obtain solutions with the desired properties, it is necessary to study the main physical and electrochemical processes occurring in the activator. Also, 
it is necessary to develop computer models of electric activators, on which it was possible to reproduce the main ongoing processes, comparing them with the results of experiments.

\section{Materials and methods}

The analysis of physical and chemical processes was carried out on the example of a non-flowing electric activator with a total volume of 1 liter of liquid. Simulation of the electrical activation process was performed using the Comsol 5.4 software product. The results of some studies were presented earlier [24]. The geometric model was a cylinder containing electrodes and a diaphragm (Fig.1, a). All analyses were performed on half of the activator model in order to reduce the calculation time. A direct current is connected to the electrodes 1 and 2, which passes through the electrolyte through the diaphragm 3. There is an air space above the electrolyte level (4), where the gases are released during electrolysis. The type of electric current lines is shown in Figure 1, b.
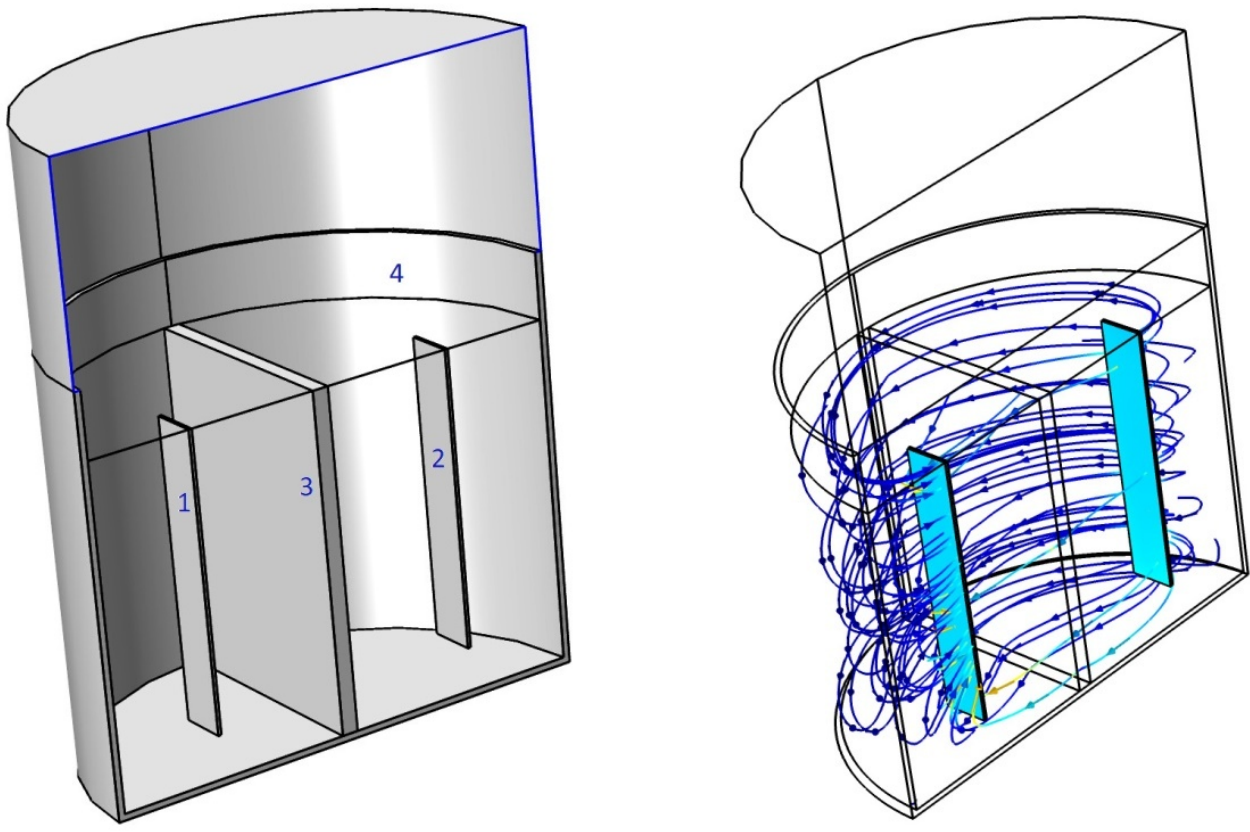

Fig. 1. Type of the electric activator in the section (left) and type of the power lines of electric current in it (right)

Since the flow of current through the liquid will be heated, we describe this process by equations. First of all, heat will be generated due to water heating as a current conductor, the so-called Joule heating, as well as due to chemical reactions [25]:

$$
\rho \cdot c_{p} \cdot \frac{\partial T}{\partial t}+\rho \cdot c_{p} \cdot u \cdot \nabla T+\nabla q_{l}=Q_{J}+\sum Q_{c h}
$$

where $\rho, c_{p}$ - density and heat capacity of medium, $\mathrm{kg} \cdot \mathrm{m}^{-3}$ and $\mathrm{J} \cdot(\mathrm{kg} \cdot \mathrm{K})^{-1}$ respectively;

$u$ - flow speed, $\mathrm{m} \cdot \mathrm{s}^{-1}$;

$q_{l}=-\lambda \nabla T-$ density of heat flow, $\mathrm{W} \cdot \mathrm{m}^{-2}$

$\lambda$ - coefficient of heat conductivity of liquid, $\mathrm{W} \cdot(\mathrm{m} \cdot \mathrm{K})^{-1}$;

$Q_{J}$ - Joule heating, $\mathrm{W} \cdot \mathrm{m}^{-3}$;

$\Sigma Q_{c h}$ - total quantity of released and absorbed heat due to chemical reactions, $\mathrm{W} \cdot \mathrm{m}^{-3}$.

The intensity of heat discharges due to chemical reactions is determined by the formula:

$$
\sum Q_{c h}=\sum_{m} \alpha_{v, m} Q_{m},
$$

where $Q_{m}$ - intensity of heat discharge in one $m$ reaction, $\mathrm{W} \cdot \mathrm{m}^{-2}$;

$\alpha_{v, m}$ - coefficient of specific surface, $\mathrm{m}^{2} \cdot \mathrm{m}^{-3}$.

The intensity of heat discharge in one reaction is determined by the formula [25]: 


$$
Q_{m}=\left(\phi_{s}-\phi_{l}-E_{c q, m}+T \frac{\partial E_{c q, m}}{\partial T}\right) i_{m},
$$

where $E_{c q, m}-$ equilibrium potential of the reaction, $\mathrm{V}$;

$i_{m}$ - density of current for the present reaction, $\mathrm{A} \cdot \mathrm{m}^{-2}$.

The equation of the flow of liquid medium associated with thermal convection can be described using the Navier-Stokes equations (continuity of medium and equation of motion) [24]:

$$
\left\{\begin{array}{l}
\frac{\partial \rho}{\partial t}+\nabla \cdot(\rho u)=0 \\
\rho \frac{\partial u}{\partial t}+\rho u \cdot \nabla u=-\nabla p+\nabla \cdot\left(\mu\left(\nabla u+(\nabla u)^{T}-\frac{2}{3} \mu(\nabla \cdot u) I\right)\right)+\rho g
\end{array},\right.
$$

where $p$-pressure, $\mathrm{Pa}$;

$\mu$ - coefficient of dynamic viscosity, Pa.s;

$I$ - unit vector;

$\rho g$ - gravity, N.

Various dissolved substances are contained in source water. Under the influence of electric current, due to diffusion and convection, they begin to move. The transport of these substances is described by the Nernst-Planck equation:

$$
\frac{\partial c_{i}}{\partial t}+\nabla \cdot\left(D_{i} \cdot \nabla c_{i}+z_{i} \cdot u_{m i} \cdot F \cdot c_{i} \cdot \nabla V\right)+R_{i},
$$

where $\quad c_{i}$ - concentration $i$ substance, $\mathrm{mol} \cdot \mathrm{m}^{-3}$;

$D_{i}-$ coefficient of diffusion $i$ вещества, $\mathrm{m}^{2} \cdot \mathrm{s}^{-1}$;

$z_{i}$ - charge of $i$ ion;

$u_{m i}-$ mobility of $i$ ion, $u_{m i}=D_{i} /(R T)$, mol $\cdot \mathrm{s} \cdot \mathrm{kg}^{-1}$;

$F$ - constant of Faraday;

$V$ - volume, $\mathrm{m}^{3}$;

$R_{i}$ - speed of chemical reaction, $\mathrm{mol} \cdot \mathrm{m}^{-3} \cdot \mathrm{s}$.

The density of current in the electrolyte is described in accordance with Faraday's law and is characterized by the equation:

$$
i_{l}=F \sum_{i=1}^{n} z_{i}\left(-D_{i} \cdot \nabla c_{i}-z_{i} \cdot u_{m i} \cdot F \cdot c_{i} \cdot \nabla V\right) .
$$

Oxidation or reduction processes occur on the electrodes. Since there is an external voltage source, the electrons move in a direction that allows the weaker oxidizer to be reduced (at the cathode) and the weaker reducing agent to be oxidized (at the anode). Several electrochemical reactions occur in the cathode and anode chambers. The number of these reactions depends on the water content of the number of trace elements, and all of them are difficult to describe. Individual reactions do not significantly affect the parameters of activated water. Therefore, let us consider the most typical reactions for these research objects.

Firstly, chlorine-containing compounds are formed in the anode chamber, and chlorine and oxygen are released at the electrode. In this regard, the characteristic complex of anodic chemical reactions looks as follows [24]:

$$
\left\{\begin{array}{l}
2 \mathrm{H}_{2} \mathrm{O}-4 e^{-} \rightarrow 4 \mathrm{H}^{+}+\mathrm{O}_{2} \\
2 \mathrm{Cl}^{-}-2 e^{-} \rightarrow \mathrm{Cl}_{2} \\
\mathrm{Cl}_{2}+\mathrm{H}_{2} \mathrm{O} \rightarrow \mathrm{HClO}+\mathrm{HCl} \\
\mathrm{HClO} \leftrightarrow \mathrm{H}^{+}+\mathrm{ClO}^{-} \\
2 \mathrm{ClO}_{2}+\mathrm{O}_{3}+\mathrm{H}_{2} \mathrm{O} \rightarrow 2 \mathrm{ClO}_{3}^{-}+\mathrm{O}_{2}+2 \mathrm{H}^{+} \\
\mathrm{HCl}+2 \mathrm{H}_{2} \mathrm{O}-5 e^{-} \leftrightarrow 5 \mathrm{H}^{+}+\mathrm{ClO}_{2}
\end{array} .\right.
$$


Hydrogen is released at the cathode and metals are recovered. Reactions for the formation of hydroxides and carbonates take place in the cathode chamber. Let us take as an example of the reactions for iron, calcium, and sodium for further analyses [24]:

$$
\left\{\begin{array}{l}
2 \mathrm{H}_{2} \mathrm{O}+2 e^{-} \rightarrow \mathrm{H}_{2}+2 \mathrm{OH}^{-} \\
\mathrm{Fe}^{2+}+2 e^{-} \rightarrow \mathrm{Fe} \\
2 \mathrm{H}_{2} \mathrm{O}+2 \mathrm{Na}^{+}+2 e^{-} \rightarrow \mathrm{H}_{2}+2 \mathrm{NaOH} \\
\mathrm{Ca}^{2+}+2 \mathrm{HCO}_{3}^{-} \leftrightarrow \mathrm{CaCO}_{3}+2 \mathrm{H}_{2} \mathrm{O}+\mathrm{CO}_{2}
\end{array}\right.
$$

The next stage of researches is to configure the software interfaces. The equations of thermal processes are solved using the "Heat Transfer" physical block. The activator body is made of plastic, the electrodes are the steel cathode, the anode is ruthenium-coated steel, and the diaphragm is a tarpaulin. The initial temperature of all elements is $20^{\circ} \mathrm{C}$. Decisions on the movement of the liquid as a result of thermal convection were made in the "Laminar Flow" interface. All electrolytic processes were modeled in the "Tertiary Current Distribution" interface. Based on analyses of available water, initial conditions were set for concentrations of the following chemical elements and compounds: $\mathrm{Na}$, $\mathrm{Cl}, \mathrm{Mg}, \mathrm{SO}_{4}, \mathrm{HCO}_{3}, \mathrm{~K}, \mathrm{Ca}, \mathrm{Cl}_{2}, \mathrm{O}_{2}, \mathrm{H}_{2}, \mathrm{Fe}+, \mathrm{HClO}, \mathrm{HCl}, \mathrm{ClO}_{2}, \mathrm{CaCO}_{3}, \mathrm{O}_{3}, \mathrm{NaOH}, \mathrm{ClO}_{3}, \mathrm{ClO}$. The diffusion coefficients of elements were taken from the literature data. In the "Electrode Surface" interfaces, the formation of oxygen, ozone and chlorine was simulated at the anode, and the reduction of hydrogen and iron was simulated at the cathode. The "Reaction" interface receives the velocities of the main chemical reactions from a separate science "Chemistry". For the complex solution of all equations, all interfaces will be connected via the multiphysical blocks "Electrochemical Heating" and "Nonisothermal Flow".

After starting the simulation process, a set of solutions of the model equations was obtained and corresponding plots and images were constructed. Studies of the material obtained were carried out on separate physical and chemical processes.

The process of formation of chlorine-containing compounds, which are the basis of the bactericidal component of this solution, is in progress in the anolyte. For example, Figure 2 shows graphs of changes in $\mathrm{HCl}$ and $\mathrm{HClO}$ concentrations, where their concentration increases from 0 to $0.001 \mathrm{~mol} \cdot \mathrm{m}^{-3}$. At the same time, $\mathrm{ClO}$ formation from sulfurous acid $\mathrm{HClO}$ is organized in the model. The formation of $\mathrm{ClO}_{2}, \mathrm{ClO}_{3}$ is very slow, since they appear as a result of secondary reactions, and therefore the concentrations of these elements have lower values compared to $\mathrm{HCl}$ (by several orders of magnitude). Dissociation of the $\mathrm{HClO}$ acid leads to the formation of $\mathrm{ClO}$, but the acid itself has the same value of concentrations in the anolyte. For example, Figure 2 (right) shows the image of $\mathrm{HClO}$ concentration after 16 minutes of an activator operation, and you can see a narrow zone of elevated concentrations of the order of $35 \cdot 10^{-7} \mathrm{~mol} \cdot \mathrm{m}^{-3}$. At the same time, this acid is also in the catholyte and it does not change the concentration much over time and is at the level of $10 \cdot 10^{-7} \mathrm{~mol} \cdot \mathrm{m}^{-3}$.
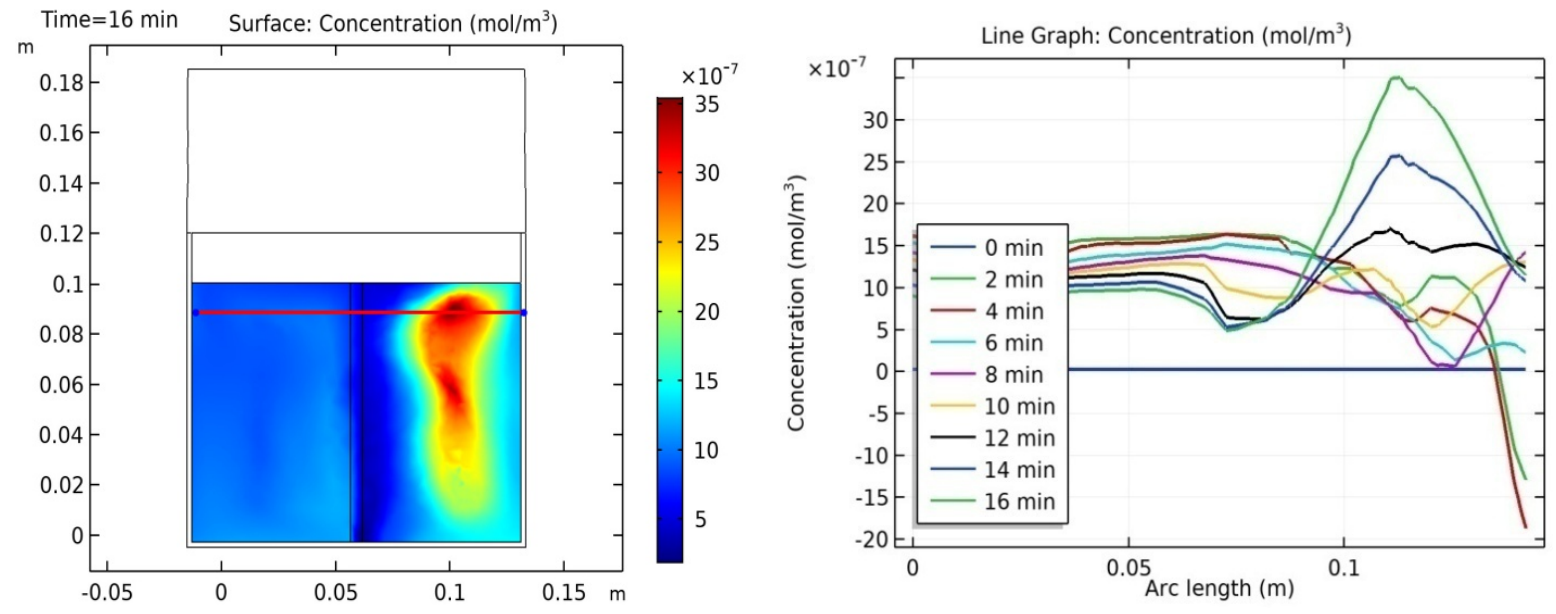

Fig. 2. Images of $\mathrm{HClO}$ concentrations in the anolyte after 16 minutes of operation (left) and graphs of changes in $\mathrm{HClO}$ concentration along the activator diameter over time (right) 
The analysis of fluid velocities due to thermal convection showed that their average value is at the level of $2 \cdot 10^{-3} \mathrm{~m} \cdot \mathrm{s}^{-1}$, and the highest velocities are observed in the anode chamber and closer to the water surface - up to $4 \cdot 10^{-3} \mathrm{~m} \cdot \mathrm{s}^{-1}$.

Graphs of changes in iron concentration were studied. An incision along the horizontal line of the activator (Fig.3) showed changes in concentrations at the anode and cathode. The obtained graphs show the process of reducing iron at the cathode and show that over time the concentration of this element increases in the cathode chamber and the maximum value near the cathode is $6.88 \cdot 10^{-3} \mathrm{~mol} \cdot \mathrm{m}^{-3}$
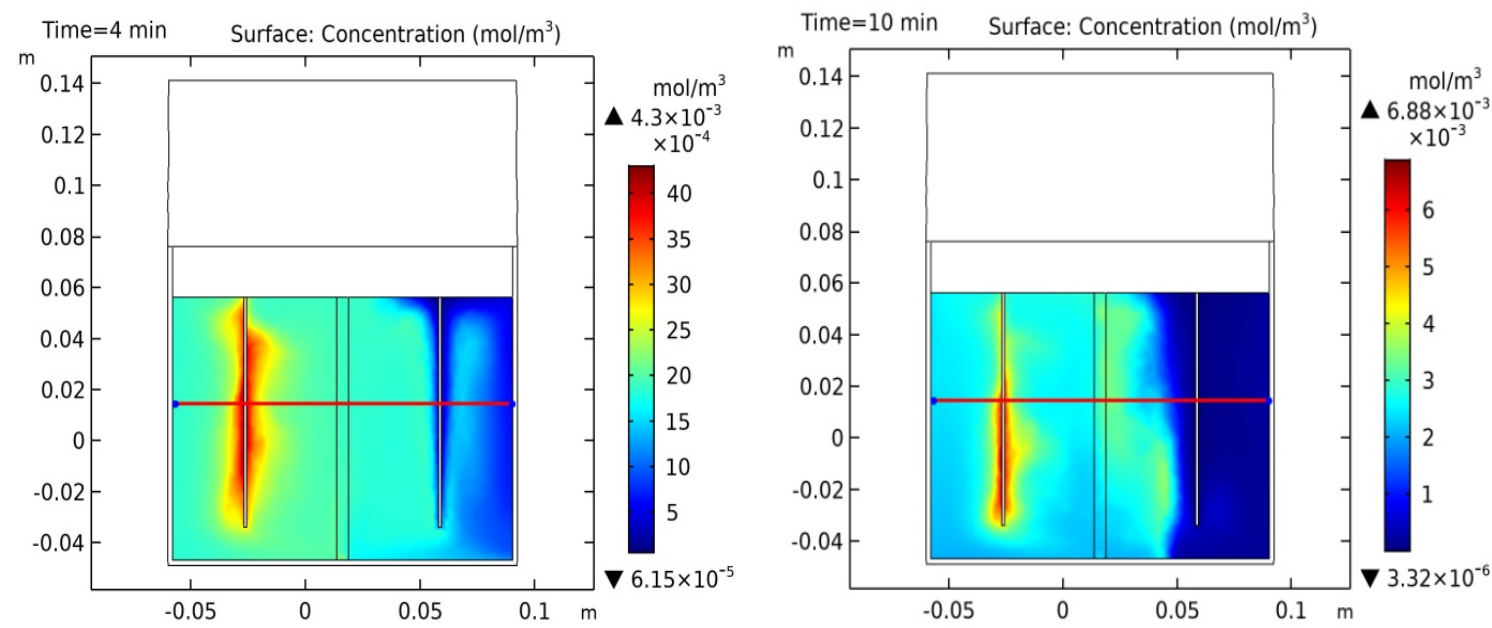

Fig. 3. Images of iron concentrations in the anode and cathode chambers (cut through the middle of the activator) after 4 minutes (left) and 10 minutes (right) of operation

The process of formation of hydroxides of sodium, calcium and magnesium takes place in the cathode chamber. In this regard, the formation of hydroxides was modeled only on the sodium content. Other elements can be modeled similarly. So, Figure 4 shows images of the formation of hydroxides of sodium through 4 and 12 minutes of the activator operation, where it is seen that the increased concentration is observed near the cathode and diaphragm from the part of the anolyte, and anode concentration is very low.
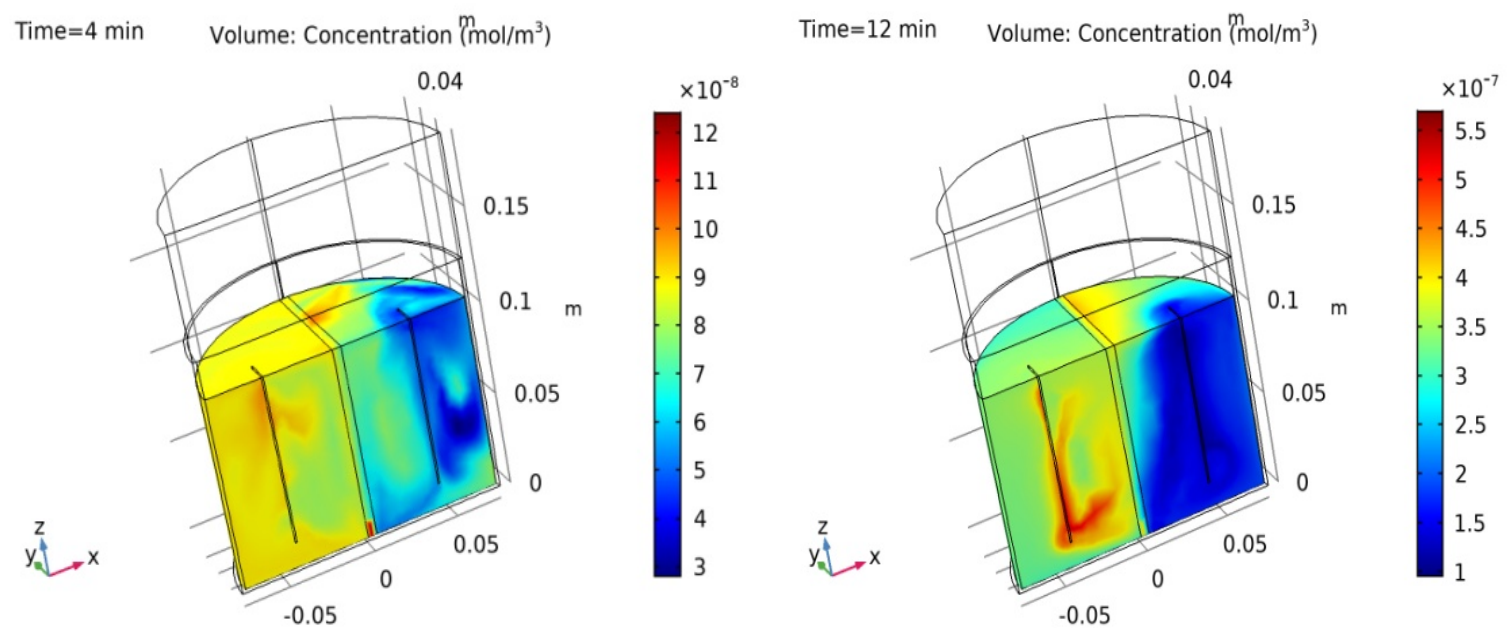

Fig. 4. Images of sodium hydroxide formation after $\mathbf{4}$ and 12 minutes of the activator operation

The formation of the chlorine gas fraction in the anolyte is shown in Figure 5, where you can see the following: by 6 minutes the chlorine gas is mainly located behind the anode and has a concentration of up to $0.075 \mathrm{~mol} \cdot \mathrm{m}^{-3}$; by 16 minutes some of the gas has spread throughout the anolyte and is partially dissolved with the maximum concentration being $0.035 \mathrm{~mol} \cdot \mathrm{m}^{-3}$. 


\section{Results and discussion}

The laboratory unit with geometric dimensions that match the dimensions of the computer model was assembled for experimental researches. The purpose of the laboratory tests was to check the theoretical positions and simulation results for water electrical activation. The temperature, $\mathrm{pH}$, and concentration of $\mathrm{K}, \mathrm{CA}, \mathrm{Cl}, \mathrm{Na}$ and $\mathrm{Mg}$ ions were measured using the "Expert-001c" water analyzer with the appropriate set of electrodes.

For example, Figure 5 shows graphs for the concentrations of magnesium and calcium in the electrolyte. These images show that the model and experimental graphs mostly have a good match, especially after the 12th minute. There is a decrease in the concentrations of these elements in this part of the activator due to their transfer to the catholyte chamber. Experimental values have fluctuations in the first moments of time, but the trend coincides with the theoretical graph. The relative error of discrepancies between the values of the theory and the experiment at the end of the non-stationary period is in the range from 2 to $6 \%$. The maximum deviation of data is observed in the time interval from 5 to 12 minutes on the first chart and from 2 to 8 minutes on the second. Such deviations can be explained by a large number of ongoing chemical reactions and their different rates of flow. In this case, many intermediate unstable compounds are formed, which are quickly disintegrated.
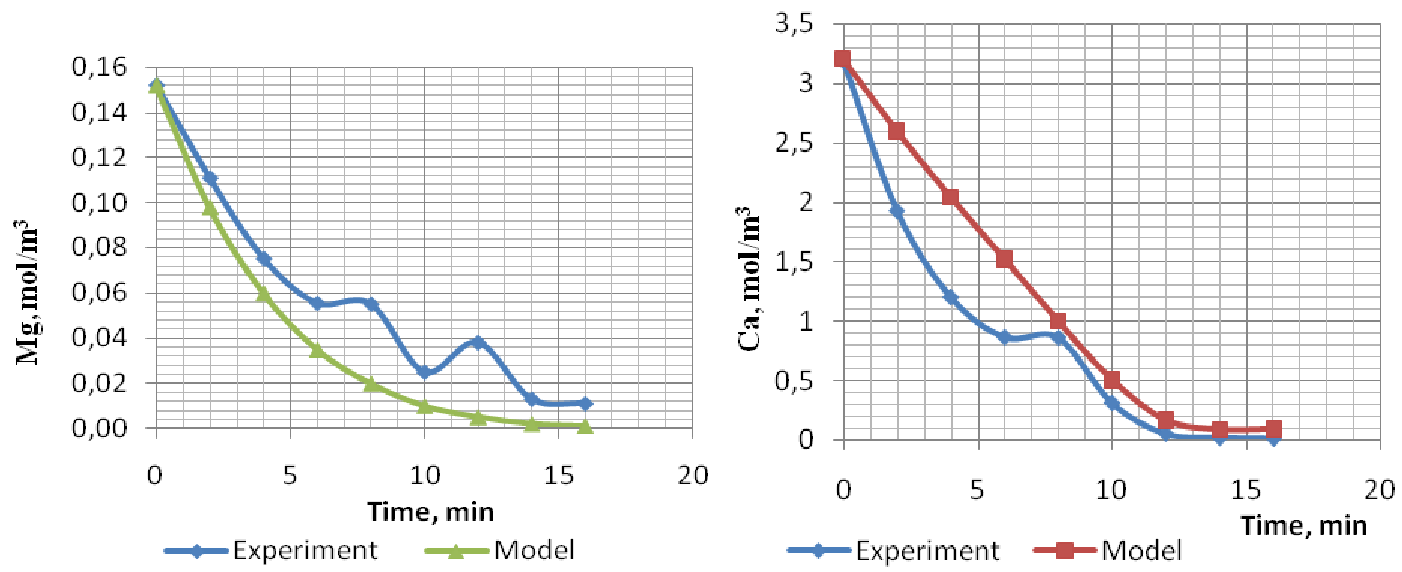

Fig. 5. Graphs of time-dependent changes in magnesium concentrations (left) and calcium (right)

Using the example of magnesium, chemical reactions of magnesium carbonate formation were added to the model and the comparative graphs are shown in Figure 6. As it can be seen from this figure, when modeling electrolysis without taking into account chemical reactions of magnesium carbonate formation, the magnesium concentration increases, which is not consistent with the experiment (Fig. 6 left). By taking into account these reactions in the simulation, we obtain a good coincidence of theory with experimental data from the 8th minute (Fig. 6 right). Thus, our experiments confirm the statement of formation of carbonates in scientific literature.
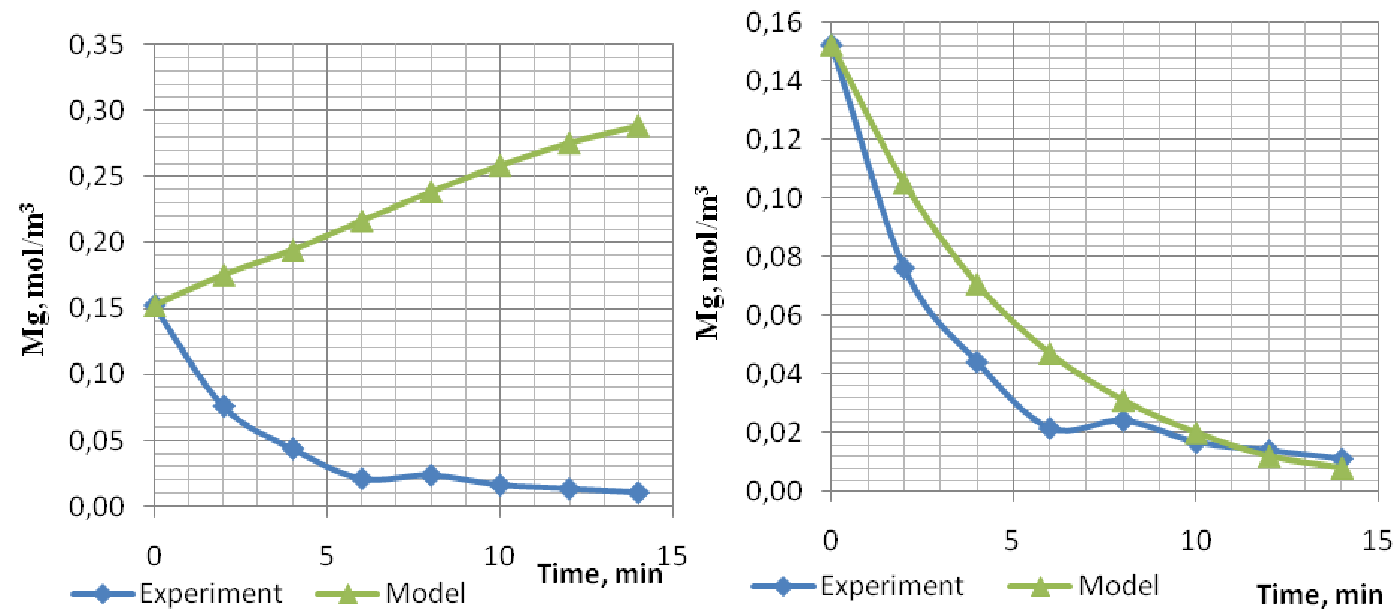

Fig. 6. Graphs of the dependence of changes in magnesium concentrations without modeling the formation of carbonates (left) and with their formation (right) from time 
Other chemical compounds were analyzed similarly. The experiments confirmed almost all changes in the concentrations of the main elements with a sufficient level of accuracy.

\section{Conclusions}

Analysis of changes in $\mathrm{HCl}$ and $\mathrm{ClO}$ concentrations in anolyte shows that their concentration increases from 0 to $0.001 \mathrm{~mol} \cdot \mathrm{m}^{-3}$. The formation of $\mathrm{ClO}_{2}, \mathrm{ClO}_{3}$ is slower, since they appear as a result of secondary reactions, and therefore the concentrations of these elements have lower values compared to $\mathrm{HCl}$. Dissociation of the $\mathrm{HClO}$ acid leads to the formation of $\mathrm{ClO}$, so the acid itself has a low rate of formation in the anolyte, so the concentration of $\mathrm{HClO}$ in the anolyte can reach the order of $35 \cdot 10^{-7} \mathrm{~mol} \cdot \mathrm{m}^{-3}$ after 16 minutes of the activator operation.

Modeling of the formation of hydroxides in the catholyte on the example of sodium was carried out, and studies have shown that after 4 and 12 minutes of the activator operation, an increased concentration is observed near the cathode and the diaphragm on the part of the anolyte. The concentration of sodium hydroxide in the catholyte reaches $65 \cdot 10^{-8} \mathrm{~mol} \cdot \mathrm{m}^{-3}$ after 16 minutes of operation.

The experimental values of the concentrations of sodium, potassium, calcium and magnesium ions in the anolyte and catholyte have fluctuations in the first moments of time (up to 12 minutes), which indicates a significant number of chemical reactions with these ions and the instability of the resulting compounds. Despite the time fluctuations in the experimental concentrations of these ions, the resulting trend of these changes coincides with the model data. The results obtained for the hydrogen index, concentrations of calcium, magnesium and chlorine in the anolyte indicate that by 12 minutes the operation of the activator becomes stationary and most of the ions end up being transported through the diaphragm.

\section{References}

[1] Bakhir V. M., Leonov B. I., Panicheva S. A., Prilutskiy V.I., Shomovskaya N. Yu. Efficiency and safety of chemical means for disinfection, pre-sterilized purification and sterilization. Disinfection, 2003, No. 1, pp. 29-36.

[2] Prilutsky V.I., Dolgopolov V.I., Barabash T.B. Anolytes in the market of disinfection preparations: you will not make a mistake in choosing! Medical alphabet. Epidemiology and hygiene, 2013, No 3. pp. 52-61.

[3] Hricova D, Stephan R, Zweifel C. Electrolyzed water and its application in the food industry. J. of Food Protection, 2008, vol. 71. pp. 1934-1947.

[4] Stopforth J D, Mai T, Kottapalli B, Samadpour M. Effect of acidified sodium chlorite, chlorine, and acidic electrolyzed water onto leafy greens. J. of Food Protection, 2008, vol. 71. pp. 625-628.

[5] Udompijitkul P, Daeschel M A, Zhao Y. J. of Food Science, 2007, vol. 72. pp. 397-406.

[6] Zhao Y. et al. Plasma-Activated Water Treatment of Fresh Beef: Bacterial Inactivation and Effects on Quality Attributes. IEEE Transactions on Radiation and Plasma Medical Sciences, 2020, vol. 4, No. 1. pp. 113-120.

[7] Liu M., Zhou B., Wang Z. Study on Catalytic Ozonation/BAC Process for Advanced Drinking Water Treatment. 3rd International Conference on Bioinformatics and Biomedical Engineering, Beijing, 2009. pp. 1-4.

[8] Umimoto K., Emori Y., Fujita H., Jokei K., Evaluation of strong acidic electrolyzed water for the disinfection. IEEE EMBS Asian-Pacific Conference on Biomedical Engineering, Kyoto, Japan, 2003. pp. 360-361.

[9] Gurbanov E. Electrophysical methods of bacteriological disinfection of water medium. IEEE 41st International Conference on Plasma Sciences (ICOPS) held with 2014 IEEE International Conference on High-Power Particle Beams (BEAMS), Washington, DC, 2014.

[10] Sirenko S.P., Grigoryeva N.N., Chepel L.M., Shakhbazov V.G., Fisun A.I., Belous O.I. Effects of EM-radiation activated water on biological objects. 14th International Crimean Conference "Microwave and Telecommunication Technology" (IEEE Cat. No.04EX843), Sevastopoll, Crimea, Russia, 2004. pp. 717-718. 
[11]Jun Li, Qiang Liu, Shuya Zhang, Songtao Yao, Shuang Yang. Study on the removal of nitrate from water by $\mathrm{Fe} / \mathrm{C}$ micro-electrolysis process. Second International Conference on Mechanic Automation and Control Engineering, Hohhot, 2011. pp. 3588-3591.

[12] Jing G., Xing L., Li S. Study of Mathematical Model in Electrodialysis of Desalination. 4th International Conference on Bioinformatics and Biomedical Engineering, Chengdu, 2010. pp. 1-4.

[13] Jing G., Liu Y., Han C., Zhu Q. Mathematical Modeling for Desalination by Electrodialysis. 3rd International Conference on Bioinformatics and Biomedical Engineering, Beijing, 2009. pp. 1-4.

[14] Koseki M., Tanaka Y., Noguchi H., Nishikawa T. Effect of $\mathrm{pH}$ on the Taste of Alkaline Electrolyzed Water. Journal of Food Science, vol. 72, No 5, 2007. pp. S298-S302.

[15] Hsu S. Y. Effects of flow rate, temperature and salt concentration on chemical and physical properties of electrolyzed oxidizing water. Journal of Food Engineering, No. 66, 2005. pp. 171176.

[16] Al-Haq M.I., Sugiyama J., Isobe S. Review Applications of Electrolyzed Water in Agriculture \& Food Industries. Food Science and Technology Research, 2005, vol. 11(2). pp. 135-150.

[17] Fabrizio K.A., Sharma R.R., Demirci A. et al. Comparison of electrolyzed oxidizing water with various antimicrobial interventions to reduce Salmonella on poultry. Poultry Sci, 2002, vol. 81, pp. 1598-1605.

[18]Forghani F., Park J.H., Oh D.H. Effect of water hardness on the production and microbicidal efficacy of slightly acidic electrolyzed water. Food Microbiology, 2015, vol. 48. pp. 28-34.

[19] Graça A., Abadias M., Salazar M. et al. The use of electrolyzed water as a disinfectant for minimally processed apples. Postharvest Biology and Technology, 2011, vol. 61(2-3). pp. 172177.

[20] Oskin S.V. Electrotechnological trends of ecological safety increase of agricultural crops. Emergencies: industrial and ecological safety, 2010, No. 1-2. pp. 107-115.

[21] Oskin S.V., Ovsyannikov D.A. The need to use environmentally friendly methods for treating bee colonies from existing diseases. Emergencies, 2014, No. 2(18). pp. 134-144.

[22] Oskin S.V. Innovative ways to improve ecological safety of agricultural products. Land management, cadastre and land monitoring, 2013, No. 8(104). pp. 75-80.

[23] Oskin S.V., Tsokur D.S. The use of electrical active water in technological process of ecologically safe cultivation of vegetables in the conditions of close ground. Emergencies: industrial and ecological safety, 2014, No. 2(18). pp. 148-154.

[24] Oskin, S.V., Tsokur, D.S. Preparation of disinfectant solution for use in agricultural production and processing industry. J. Phys.: Conf. Ser. 1353, 12035. 10.1088/1742-6596/1353/1/012035.

[25] CFD Module User's Guide. COMSOL. 